\title{
New information on two Late Cretaceous (Turonian) fishes from Lac des Bois, Northwest Territories, Canada
}

\section{Alison M. Murray ${ }^{\star, 1}$ and Stephen L. Cumbaa ${ }^{2}$}

${ }^{1}$ Department of Biological Sciences, University of Alberta, Edmonton, AB, T6G 2E9, Canada, ammurray@ualberta.ca 2Palaeobiology, Canadian Museum of Nature, PO Box 3443, Station D, Ottawa, ON, K1P 6P4, scumbaa@mus-nature.ca

\begin{abstract}
Fishes from Turonian deposits at Lac des Bois, Northwest Territories, Canada, have previously been described based on material from calcareous mudstone concretions collected in 1969. A more recent collecting trip to the locality in 2010 led to the discovery of additional fossil fishes in a shale layer. These fishes, preserved in a different manner from the earlier collections, provide new information and allow reinterpretations of two previously described fishes, Aquilopiscis wilsoni (Pachyrhizodontidae) and Avitosmerus canadensis (Euteleostei). Although the new material allows a better understanding of these two fishes, it does not change our ideas about their relationships. Avitosmerus canadensis remains in the Euteleostei with relationships uncertain, and Aquilopiscis wilsoni is confirmed as a member of the Pachyrhizodontidae.
\end{abstract}

Key Words: Crossognathiformes; Euteleostei; North America; Western Interior Seaway

\section{INTRODUCTION}

Fossil fishes have been known from Turonian deposits at Lac des Bois, Northwest Territories since 1968 when geologists studied the area and found fossil remains. In 1969, David Bardack undertook the first concerted effort to collect fossils from these deposits. The fossils collected by Bardack and his team were almost exclusively recovered from calcareous concretions, collected in situ and where tumbled down along the base of a kilometre-long shale outcrop. From this collection, several fishes were named including Avitosmerus canadensis Fielitz, 2002, a small euteleost, Aquilopiscis wilsoni Cumbaa and Murray, 2008, a pachyrhizodontid, and Ornatipholis sahtu Cumbaa and Murray, 2008, an enchodontoid. Other fishes reported from the locality are an unidentified caturid amiiform, Ichthyodectes ctenodon (Ichthyodectiformes), Osmeroides sp. (Elopiformes) and the aulopiforms Enchodus gladiolus, E. petrosus and Cimolichthys sp. (Fielitz 1996; Cumbaa and Murray 2008). The locality was again visited by our field party in 2010. During this trip, we discovered that vertebrate and invertebrate fossils were also recoverable in situ from shales along the shore of the lake, 15 to 20 metres away from the base of the cliff, from just above water level to the practical limit of our quarrying, about 15 to $20 \mathrm{~cm}$ below the water table. Estimating from field photographs supplied by David Bardack from his 1969 expedition, the level of Lac des Bois in 2010 was 1.5 to 2

*corresponding author

Published February 62015

(c) 2015 by the authors

submitted October 28 2014; revisions received January 19 2015; accepted January 23 2015. Handling editor: Jordan Mallon. metres lower, exposing more of the dipping shales. From these shales a small acanthomorph fish, Boreiohydrias dayi, was described (Murray and Cumbaa 2013), and additional examples of Avitosmerus and Aquilopiscis that form the basis of this paper were recovered.

The preservation of the fishes in the shales is different from the preservation in the concretions, in that the shales preserve finer details and therefore provide new information about the fishes previously described from the concretions. We here present this additional information for two of the fishes previously described from the nodules, Aquilopiscis wilsoni and Avitosmerus canadensis. The new specimens preserved in the shales not only provide information on features not previously described, but also allow us to significantly change the interpretation of some features, such as the caudal fin skeleton of Avitosmerus canadensis.

\section{GEOLOGY}

The Lac des Bois locality (GSC locality 84342 , at about $\left.66^{\circ} 52^{\prime} \mathrm{N}, 125^{\circ} 22^{\prime} \mathrm{W}\right)$, is on the south shore of a small peninsula that juts out into Lac des Bois on the western side of the lake. The peninsula has greater relief than the surrounding area, with a kilometre-long, low shale cliff that crops out a few metres from the lake shore. The fossiliferous concretions come from about three-quarters of the way up the cliff. The fossiliferous shales, in contrast, were accessed from the lakeshore and even under the lake waters close to shore. Based on our correlation of the dipping sediments, the shales we sampled at the edge of the water would be $2.07 \mathrm{~m}$ below the only layer with visible concre- 
tions in 2010. Examination of Bardack's field photographs shows a second, lower, concretion-bearing layer on the cliff which was unfortunately covered by severe slumping in 2010. Extrapolating from our measurements of the dip, this second layer of smaller concretions sample by Bardack would have been within a few tens of centimetres stratigraphically of our lakeshore quarry shales.

The Lac des Bois locality has been dated as early Turonian, based on the invertebrate assemblage (Jeletzky 1969 report in Cook and Aitken 1971). The formation itself has not been named, but represents an open marine shale facies (Yorath and Cook 1981). More precise dating based on bentonite samples bracketing the fossiliferous layer, and examination of the macro-invertebrates and Foraminifera collected during the 2010 field season, are in progress.

\section{Materials}

The collections from field work in 2010 are housed in the Canadian Museum of Nature (CMN) and the University of Alberta Laboratory for Vertebrate Palaeontology (UALVP). Photographs of smaller specimens and close-ups of larger specimens were taken with a Nikon DCM1200C digital camera mounted on a Zeiss Discovery.V8 stereo microscope, with the specimens first being coated with ammonium chloride. Larger specimens were left uncoated and photographed with an Olympus FE-370 digital camera. Anatomical terminology follows traditional usage.

Anatomical Abbreviations: ach, anterior ceratohyal; ang, anguloarticular; ao, antorbital; brst, branchiostegal rays; cl, cleithrum; cor, coracoid; den, dentary; dfin pt, dorsal fin pterygiophores; ect, ectopterygoid; end, endopterygoid; epi, epioccipital; ex, extrascapular; fr, frontal; hy1-6, hypurals 1-6; hyo, hyomandibula; io2-3, infraorbitals 2-3; iop, interopercle; lac, lacrimal; le, lateral ethmoid; meth, mesethmoid; $\mathrm{mx}$, maxilla; met, metapterygoid; npu1, neural spine of first preural centrum; op, opercle; pa, parietal; pal, palatine; pch, posterior ceratohyal; pfin, pectoral fin; phy, parhypural; pmx, premaxilla; pop, preopercle; psph, parasphenoid; ptf, posttemporal fossa; pto, pterotic; ptt, posttemporal; pu12, preural centra 1-2; qu, quadrate; ret, retroarticular; sa, sesamoid articular; scl, supracleithrum; sm, supramaxilla; sn, supraneural bones; so, supraorbital; soc, supraoccipital; sop, subopercle; sph, sphenoid; sym, symplectic; u1-2, ural centra 1-2 (diural terminology); un 1-3, uroneurals 1-3; vo, vomer; ?vo tth, possible vomerine teeth.

\section{SYSTEMATIC PALAEONTOLOGY}

Order CROSSOGNATHIFORMES Taverne, 1989

Suborder PACHYRHIZODONTOIDEI Forey, 1977

Family PACHYRHIZODONTIDAE Cope, 1872

Aquilopiscis wilsoni Cumbaa and Murray, 2008

Figures 1-2
Holotype: CMN 17444.

Paratype: CMN 17443.

New Material: UALVP 55646 complete fish in part and counterpart (Fig. 1), UALVP 55647 isolated dentary, UALVP 55648 isolated dentary, and CMN 56501 anterior half of a fish in part and counterpart (Fig. 2).

\section{DESCRIPTION}

This taxon was erected based mainly on two specimens, the holotype CMN 17444, and the paratype CMN 17443, both of which were preserved in part and counterpart. An additional very poorly preserved specimen (CMN 17440) and one in which most details have become obscured through embedding in bioplastic (CMN 17461), as well as some disarticulated bones (CMN 17428) and an isolated head (CMN 17465), were also referred to this species. Most of these specimens preserve the elements as natural moulds, with some bone still present.

Compared to the original description, there are few details to add to the skull. The supraoccipital is larger than originally determined, and does appear to separate the two parietals in the midline, which is more similar to Rhacolepis than Notelops (Forey 1977: figs. 1, 12). The mesethmoid reaches farther posteriorly than previously described, to a level above the middle of the lateral ethmoid, and this latter element does not quite reach the parasphenoid. The vomer is hard to identify, but there are four large tooth sockets in specimen UALVP 55646 that are positioned anteriorly and above the area of the premaxilla, which should correspond to the vomer, indicating this bone bore several large teeth. We cannot confirm the shape of a nasal, but we confirm there is no ornamentation on any of the bones.

Similar to both Rhacolepis and Notelops (Forey 1977), the angular and articular cannot be distinguished, thus appearing to be fused together. The retroarticular is a small but robust bone at the posteroventral medial corner of the lower jaw. Details of the postcranial skeleton are much better preserved on the new material than the original specimens. The cleithrum is gently curved and quite broad ventrally but it narrows greatly at its dorsal extremity. There are 17 pectoral rays in UALVP 55646, as in the holotype. The dorsal fin preserves 15 rays (UALVP 55646) but has 17 pterygiophores, indicating the fin was longer than previously reported. The anal fin in this specimen preserves 17 pterygiophores, one more than was counted for the original material (16 based on a combined count of fin rays and pterygiophores).

In contrast to the original description, there are more vertebral centra than were counted in the holotype and paratype. These are most clear in UALVP 55646, which preserves 55 centra, including two ural centra and the first 


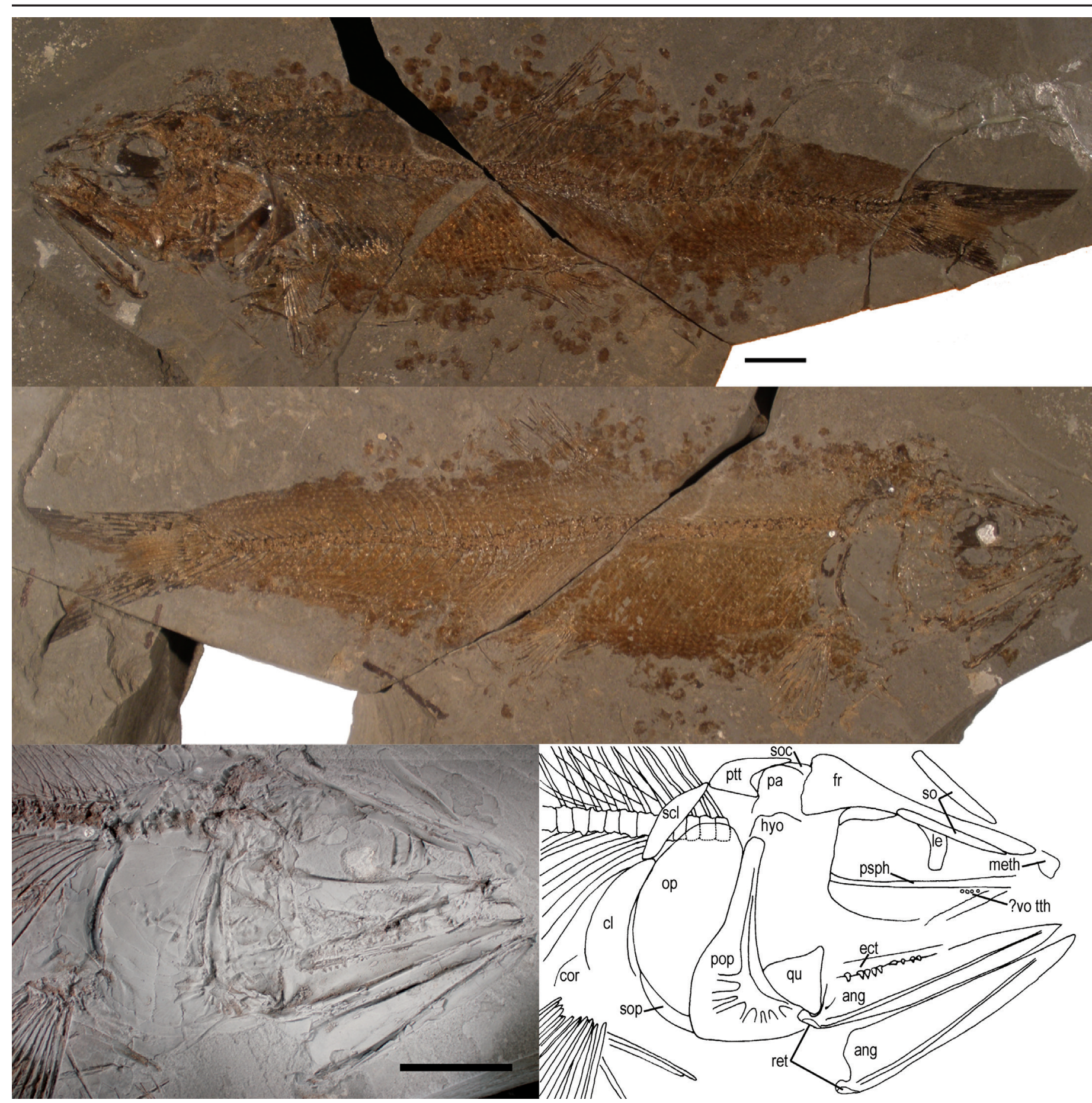

Figure 1. Aquilopiscis wilsoni, UALVP 55646. Photographs of the part and counterpart, with a close-up of the head coated with ammonium chloride and a corresponding interpretive drawing. The mesethmoid is not preserved in full on the side figured in the closeup. Scale bars equal $1 \mathrm{~cm}$.

four anteriormost centra preserved as impressions under the opercle. We could only count 42 centra in the holotype and 40 in the paratype, however the postcranial skeletons of these two specimens are predominantly weathered natural moulds making counts more difficult. In UALVP 55646 ribs are present starting on the fifth centrum through to the 35 th, for 30 pairs in total. There are 20 caudal centra, not including the two ural centra. Two series of intermuscular bones are also present on the abdominal centra. The dorsal intermuscular bones originate low down, presumably associated with the neural arch, and are six times as long as a centrum. They curve dorsally to almost reach the body wall. The ventral series of intermuscular bones appear to originate near the distal tips of the parapophyses. Neither series extends onto the caudal vertebrae. The caudal fins in the new material support the interpretation of the fin in the holotype, including the doubled spine on the second preural centrum and two epurals. The proximal portions of 


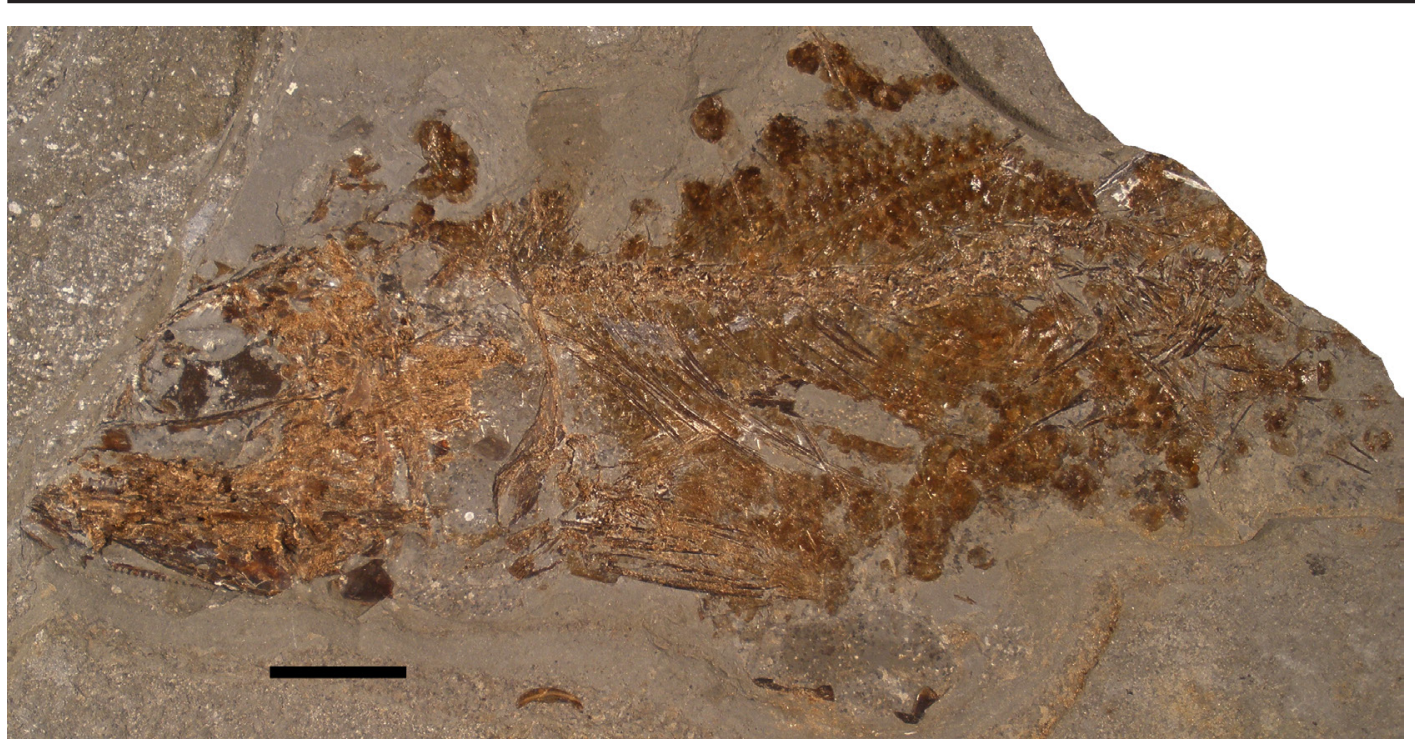

Figure 2. Aquilopiscis wilsoni, CMN 56501. Photograph of the complete specimen, which lacks the posterior portion. Scale bar equals $1 \mathrm{~cm}$.

the fin rays obscure the area where a fifth and sixth hypural would be located, so their presence or absence cannot be determined. The count of 19 principal rays $(\mathrm{i}, 9,8, \mathrm{i})$ is confirmed, and there are 12 to 13 dorsal and 11 ventral procurrent rays.

The squamation of Aquilopiscis wilsoni is also much better preserved in the new material (Figs. 1 and 2). We reported remains of 43 lateral line scales in the holotype, but conceded they were poorly preserved. In the new material, there are about 85 scales in a row from the back of the cleithrum to the end of the hypural plates. There are 26 scales in a transverse row at the level of the dorsal fin. Scales also cover bones of the skull including the frontals, parietals and supraoccipital. These are all small cycloid scales as previously reported.

\section{EUTELEOSTEI sensu Arratia, 1997 EUTELEOSTEI incertae sedis Avitosmerus canadensis Fielitz, 2002}

Figures 3-10

\section{Holotype: CMN 17456}

New Material: UALVP 55649 complete fish in part and counterpart, UALVP 55650 head only, UALVP 55651 skull in dorsal view, UALVP 55652 head in part and counterpart, UALVP 55653 isolated jaw bones, UALVP 55654 skull in dorsal view with articulated lateral head bones, UALVP 55701 almost complete fish in part and counterpart, UALVP 55702 isolated pelvic girdle in part and counterpart, UALVP 55703 almost complete fish in part and counterpart, UALVP 55704 head in part and counterpart, CMN 56502 head in part and counterpart, CMN 56503 almost complete fish in part and counterpart, CMN 56504 anterior half of body in part and counterpart, CMN 56505 isolated dentary and hyomandibula, CMN 56506 skull in dorsal view and CMN 56507 almost com-

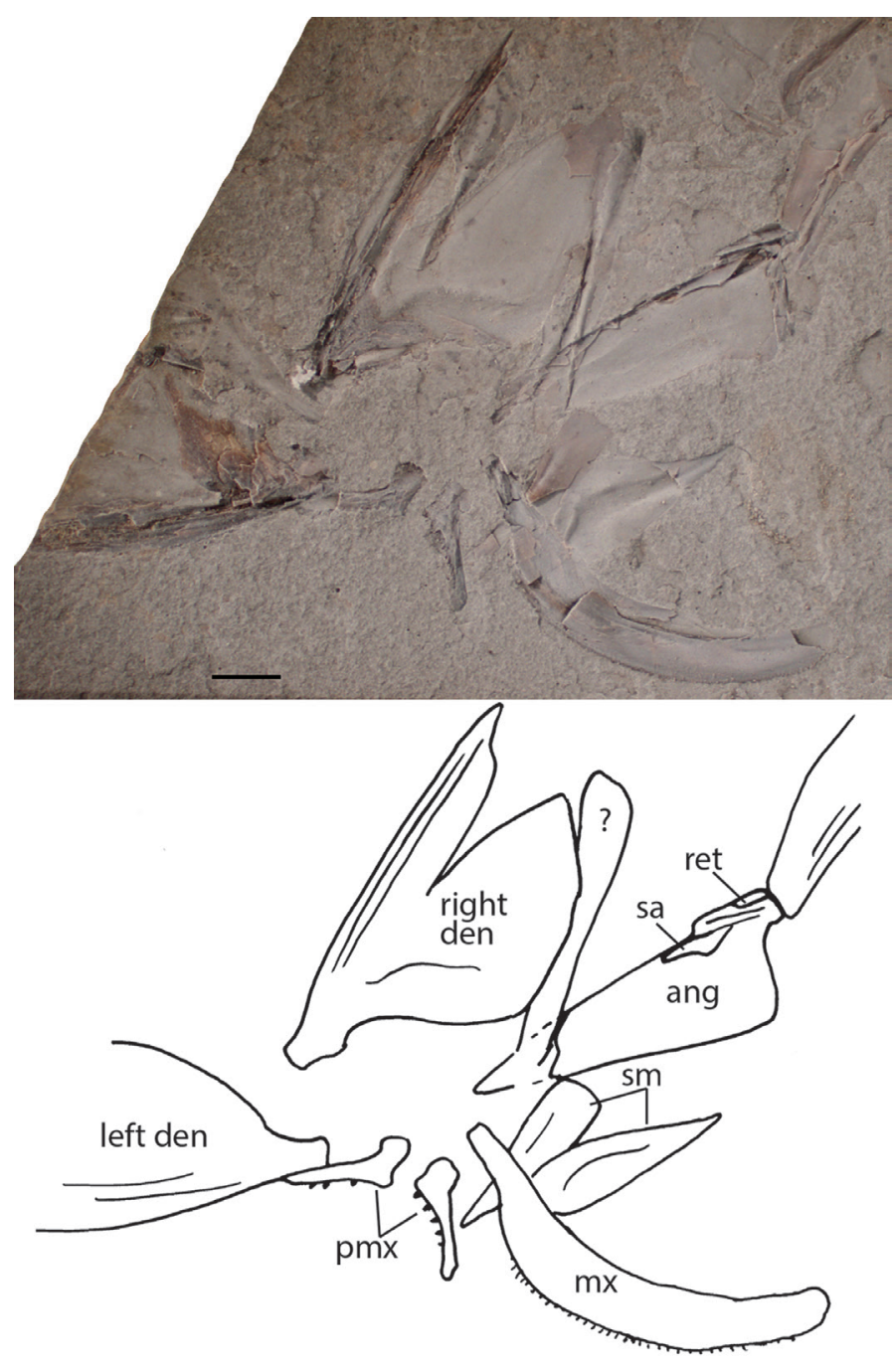

Figure 3. Avitosmerus canadensis, UALVP 55653. Photograph of the disarticulated jaw bones coated with ammonium chloride, and interpretive drawing. The elements are preserved in medial view except the right dentary, which is preserved in lateral view. Scale bar equals $2 \mathrm{~mm}$. 

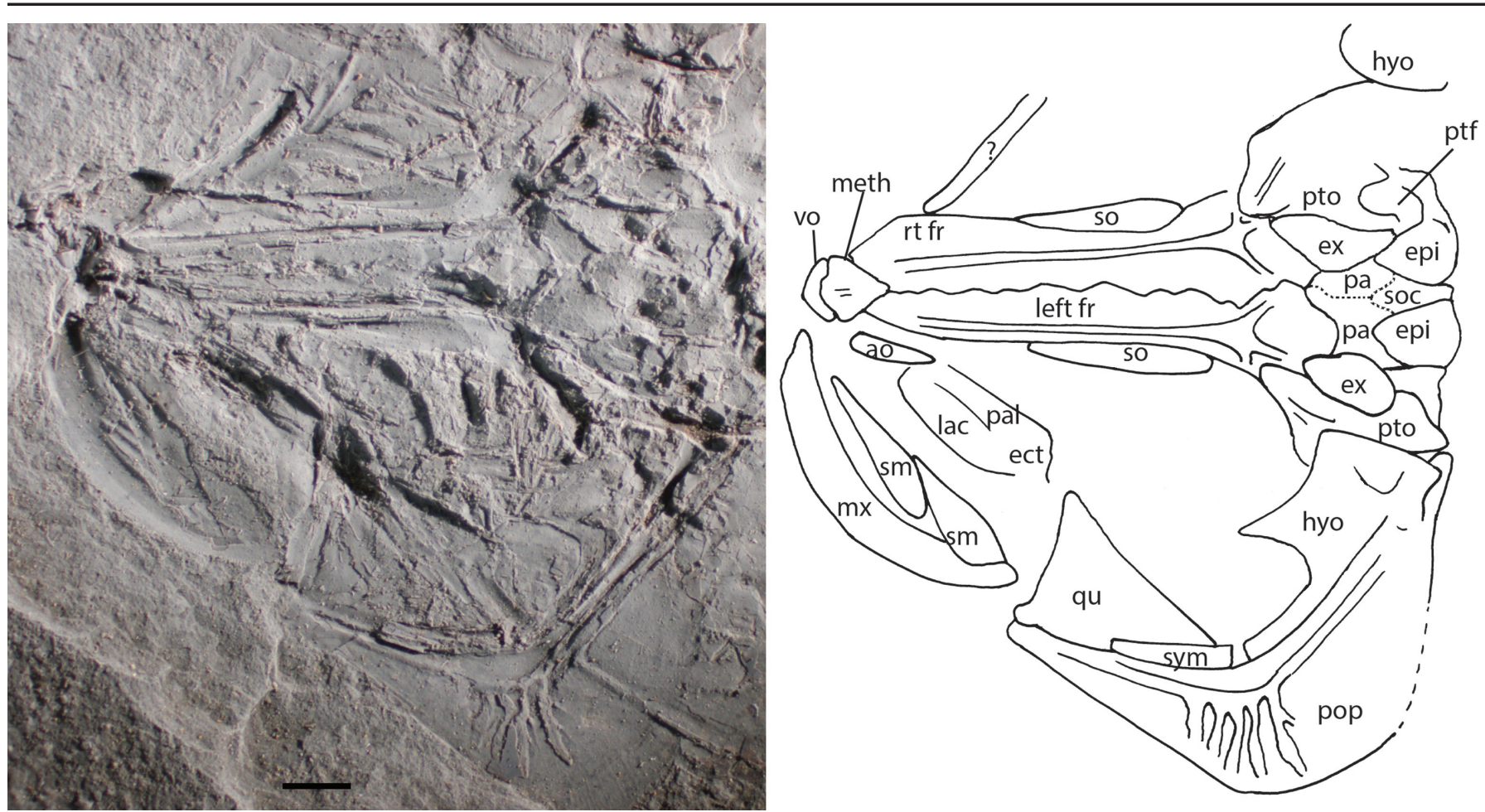

Figure 4. Avitosmerus canadensis, UALVP 55654. Photograph of the skull in dorsal view coated with ammonium chloride, and interpretive drawing. Scale bar equals $2 \mathrm{~mm}$.

plete fish in part and counterpart.

\section{DESCRIPTION}

The majority of fish specimens recovered from Lac des Bois belong to Avitosmerus canadensis; however, most of these are partially disarticulated but associated bones, possibly representing remains from coprolites. Fielitz (2002) described this new taxon based on a nearly complete specimen (the holotype, CMN 17456) and 16 other specimens varying from mostly complete to isolated heads and caudal fins. The material from the 2010 collections also consists of many more isolated heads than complete specimens. The new material includes individuals ranging from the smallest specimen, CMN 56504, with a head length of $18 \mathrm{~mm}$, to the largest specimen (UALVP 55704) having a head length of $39 \mathrm{~mm}$. Most of the 2010 specimens are smaller than the holotype and figured specimens from the 1969 collection (Fielitz 2002), suggesting smaller individuals are better preserved in the shales compared to the nodules. Several isolated elements that can be confidently attributed to $A$. canadensis were also collected, allowing the anatomy of these elements (hyomandibula, dentary, premaxilla, preopercle, and pelvic girdle) to be better known.

The jaw bones are preserved clearly in a disarticulated specimen (UALVP 55653, Fig. 3), most in medial view except the right dentary, which is preserved in lateral view. The premaxilla has a low, rounded articular head, and gently curved alveolar process. The premaxillary teeth are larger, fewer and spaced farther apart than those of the maxilla. The maxilla is less deep than previously described (Fielitz 2002:fig. 7), broadly arched with a narrow edentate head and has a fringe of small closely spaced teeth along the rest of the bone. There is a groove on the dorsal surface posteriorly for the supramaxillae. There are two supramaxillae as Fielitz (2002:fig. 7) noted, but unlike his figure, the two are of similar size and shape, with the posterior one dorsally overlapping the anterior supramaxilla (Figs. 4 and 5).

The dentary has a large (Fig. 3), wedge-shaped coronoid process and a relatively narrow ventral process that reaches slightly farther posteriorly than the coronoid process. Teeth are confined to the area around the symphysis as previously noted. Limits of the anguloarticular could not be determined before (Fielitz 2002), but in this disarticulated specimen (UALVP 55653, Fig. 3) the anguloarticular is seen to be large, with a triangular shape. There is a small retroarticular confined to the posteroventral edge of the anguloarticular. There is a small wedge of bone, just dorsal to the sensory canal, which is broken but is separate from the main part of the anguloarticular; we identify this as a sesamoid articular (as in Gaudryella gaudryi; Patterson 1970:fig. 8). The canals on the dentaries and anguloarticular are open, but there is some crushed bone so it appears that these would have been at least partially enclosed in bone in life.

Several specimens (CMN 56506, UALVP 55651, and UALVP 55654) preserve the skull in dorsal view with one in particular (UALVP 55654) preserved quite well (Fig. 


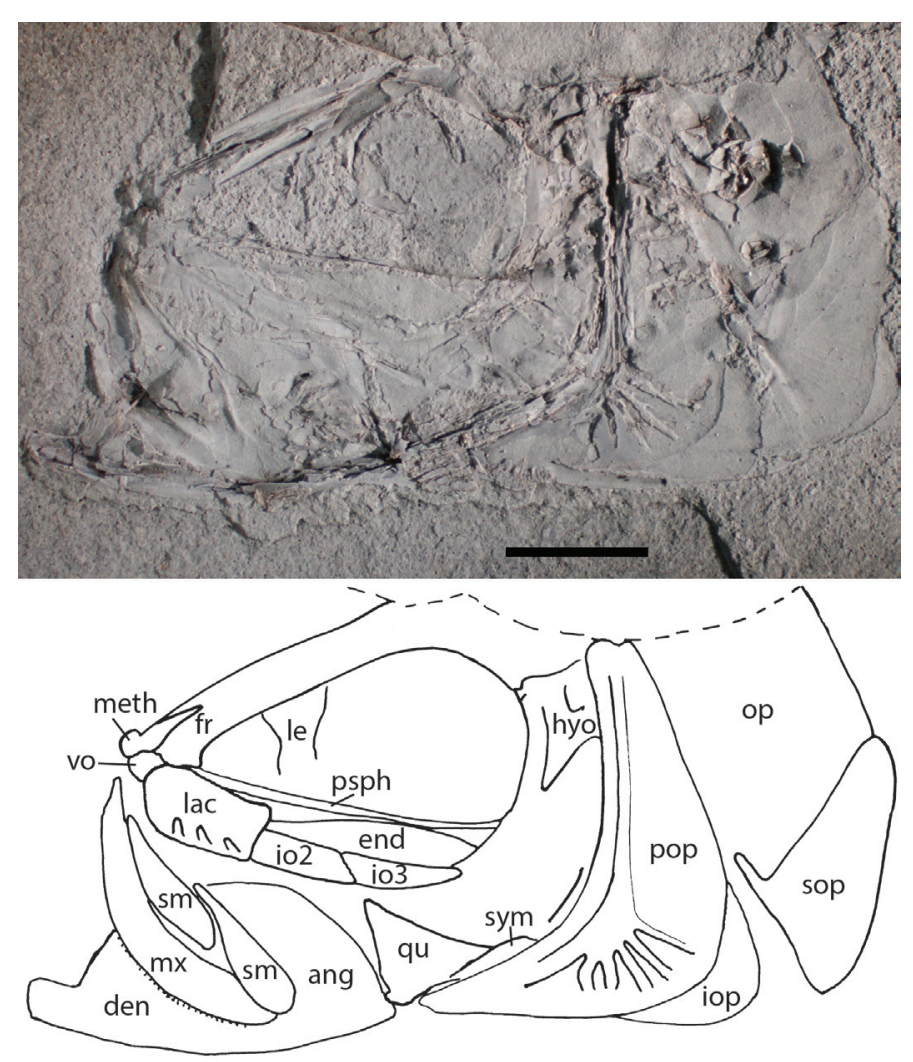

Figure 5. Avitosmerus canadensis, UALVP 55652. Photograph of the skull in lateral view coated with ammonium chloride, and interpretive drawing, showing the infraorbitals bones, opercular bones, and jaws. Scale bar equals $2 \mathrm{~mm}$.

4). The anterior tip of the vomer is visible, overlain by the mesethmoid. The posterior end of this latter is not clear. The frontals are long, and narrow anteriorly. They bear a sensory canal that splits posteriorly with one branch running medially to meet that of the other frontal, and a branch running to the canal on the pterotic. The left frontal preserves a third branch running posteriorly towards the parietal. The posterior area of the skull is less clear, and we have interpreted it in light of the specimen figured by Fielitz (2002:fig 4) and reexamined by us (CMN 17427).

Many primitive euteleosts have parietals meeting in the midline. That was the condition reported by Fielitz (2002) for $A$. canadensis, and confirmed by us on the same specimen (CMN 17427; Fielitz 2002:fig. 4). The specimen is preserved in part and counterpart; the figured side (Fielitz 2002:fig. 4) was embedded in bioplastic and acid prepared. The unprepared side retains a lot of bone and good impressions while the prepared side is mainly impressions with some bone preserved on the lateral edges. Although we agree with the figure of Fielitz (2002: fig. 4) for the most part, we believe the pterotics are actually about three-quarters of the size illustrated, as there appears to be a break posteriorly at the end of the pterotic; the rest of the bony material may represent the extrascapular bones. Specimen
UALVP 55654 (Fig. 4) shows smaller pterotics that do not reach posteriorly past the epioccipital bones. The limits of the parietals are less clear in this specimen.

Additionally, the supraoccipital figured by Fielitz (2002:fig. 4; CMN 17427) reaches farther anteriorly than Fielitz (2002:fig. 4) illustrated, separating the posterior half of the two parietal bones in the midline. The supraoccipital is diamond-shaped and constricted posteriorly by the epioccipitals. In the new material (UALVP 55654, Fig. 4) the posttemporal fossa is clearly visible between the right epioccipital and pterotic bones. On the left, the fossa is covered by the extrascapular bone.

Also visible in this specimen (UALVP 55654, Fig. 4) are long, slender supraorbital bones lateral to the frontals. They are shorter than those figured by Fielitz (2002:fig. 4), and of elongate oval shape. Of the rest of the circumorbital series, only the lacrimal is clearly preserved, and visible in UALVP 55652 (Fig. 5); it is rectangular or somewhat oval and has the sensory canal branching into three openings ventrally, in addition to the main canal running antero-posteriorly along the dorsal part of the bone. The second infraorbital bone (Fig. 5) is about the same length but narrower than the lacrimal.

The hyomandibula is preserved in position in UALVP 55654 (Fig. 4), articulating with the pterotic dorsally and a robust symplectic ventrally. Of the suspensorium, Fielitz (2002) could only describe the hyomandibula, quadrate and autopalatine. Two isolated hyomandibulae and the one associated with the dorsal skull (UALVP 55654; Fig. 4) do not have a foramen, contra Fielitz (2002); the foramen he identified may have been an area of broken bone. The dorsal head of the bone is almost flat, and we interpret it as having a single broad head that would have articulated with the braincase along its whole length, rather than having two separate condyles as described by Fielitz (2002), although in his figures (2002:figs. 2, 3, 5, 6) the element looks the same as in the new material (Figs. 4 and 5). The hyomandibulae have a pointed anteroventral projection on the anterior thin bony flange. The broad fan-shaped quadrate and palatine are as previously described. In addition, the new material preserves the ectopterygoid and bony remains of the metapterygoid and endopterygoid (CMN 56502, Fig. 6). The posterior portion of the ectopterygoid is narrow, pressed close to the quadrate and appears to have a strong bend in the middle as it angles anteriorly. The metapterygoid appears to abut the quadrate along the dorsoventral edge and fills most of the space between that bone and the hyomandibula.

Specimens CMN 56502 (Fig. 6) and 56503 preserve part of the branchial skeleton, but details are not clear. The anterior and posterior ceratohyals in both are separated by a narrow gap indicating they were joined by cartilage in life. 

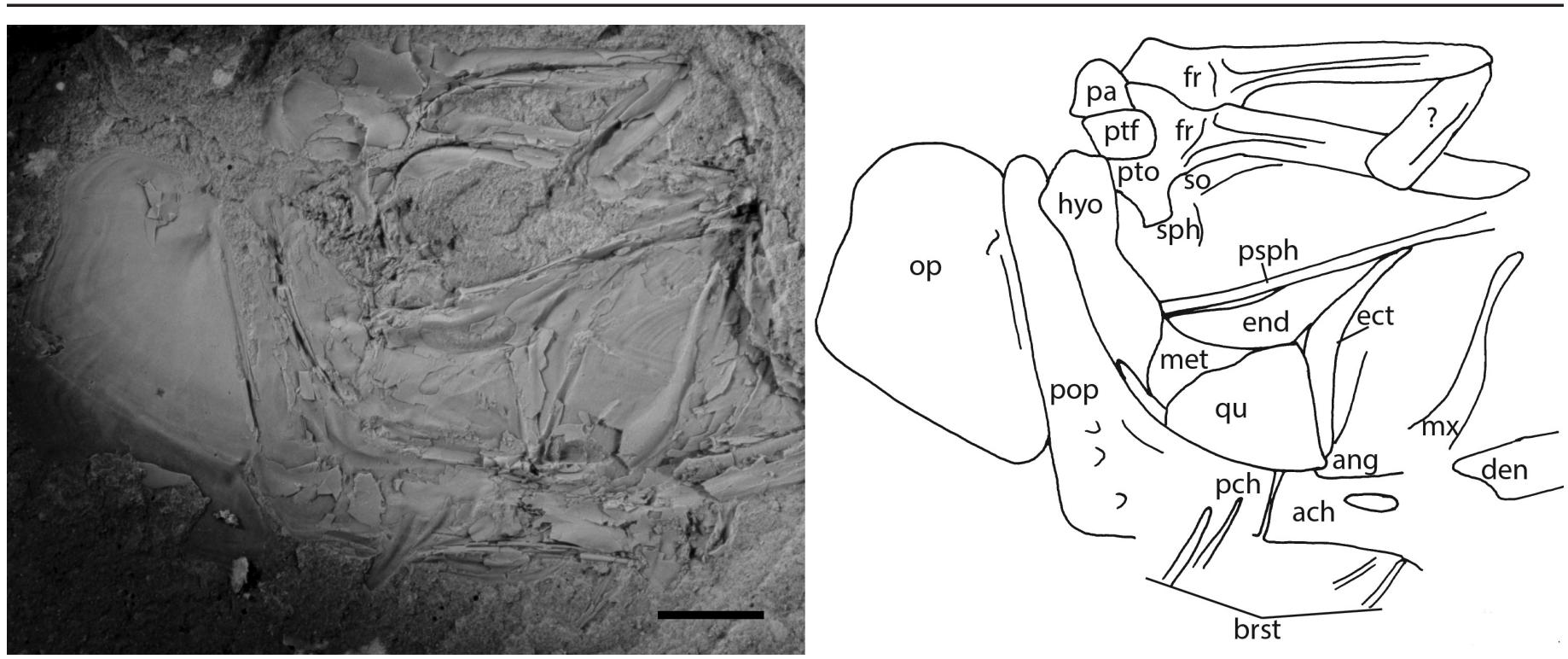

Figure 6. Avitosmerus canadensis, CMN 56502. Photograph of the skull in lateral view coated with ammonium chloride and interpretive drawing, showing the bones of the suspensorium. Scale bar equals $2 \mathrm{~mm}$.

The anterior ceratohyal in CMN 56503 (Fig. 7) is long and narrow, and appears to have a narrow beryciform foramen located towards the dorsal edge. The posterior ceratohyal is sub-triangular. There are at least nine branchiostegal rays on the anterior ceratohyal and an additional five on the posterior ceratohyal for a total of 14 branchiostegal rays in CMN 56503. There are also five branchiostegal rays (one preserved only as an impression) on the posterior ceratohyal in CMN 56502.

The opercular series of the new specimens mostly agrees with the original description. The dorsal limb of the preopercle is broader than the ventral. We are not convinced that a suprapreopercle is present; the new specimens look more like that figured by Fielitz (2002:fig. 7) in which

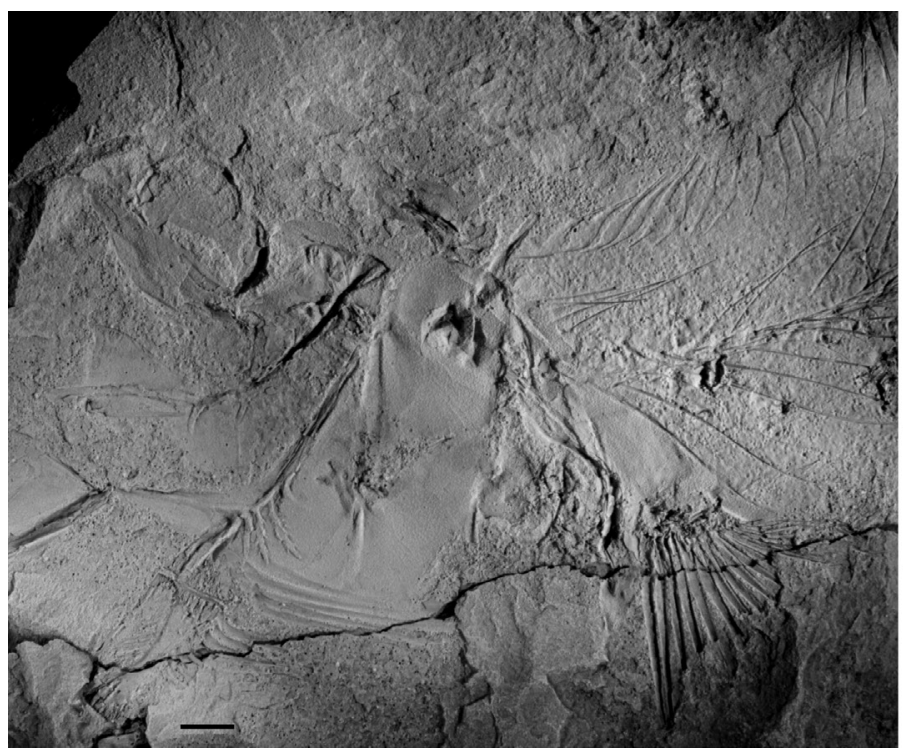

the preopercle reaches as far dorsally as the hyomandibula. However, this specimen (UALVP 55654) also shows a break at the level where Fielitz (2002:figs. 2, 5 and 6) indicates a separate suprapreopercle. This is where the preopercle overlaps the hyomandibular process for the opercle (e.g., as visible in UALVP 55654, Fig.4). We suggest that the preopercle breaks in this particular location as it is pressed down over that hyomandibular process during preservation, leading to a false impression of a separate bone being present. The enclosed sensory canal on the preopercle opens into five branches at the posteroventral corner of the bone. The interopercle is exposed at the posteroventral corner of the preopercle in this specimen, and the subopercle is also present and displaced to show a strong dorsally

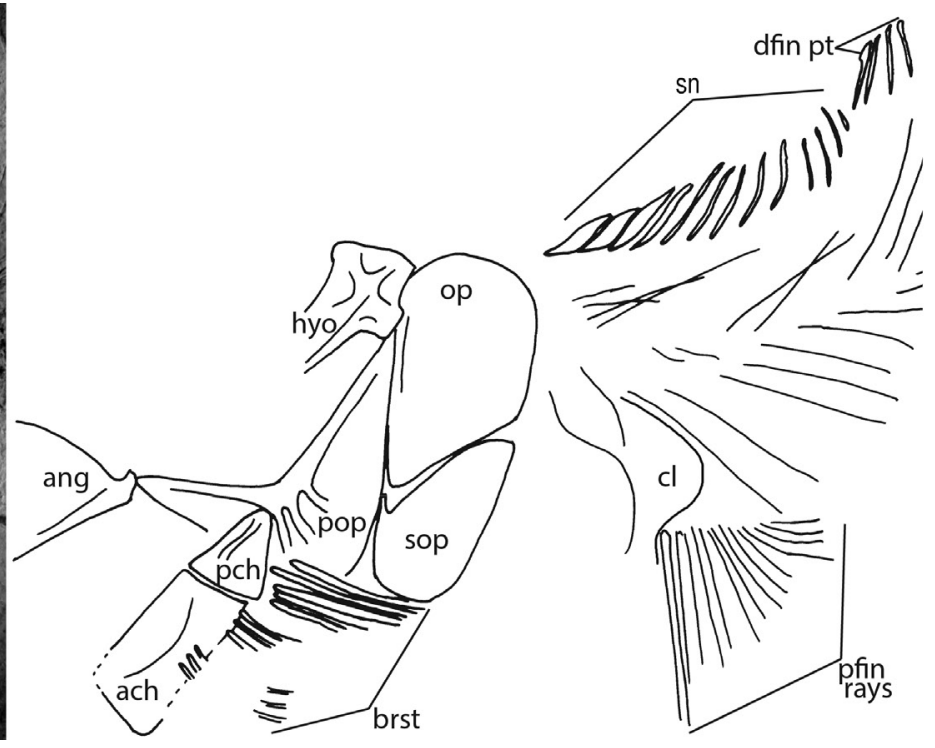

Figure 7. Avitosmerus canadensis, CMN 56503. Photograph of the head and anterior portion of the body in lateral view coated with ammonium chloride, and interpretive drawing, showing the supraneural bones and ceratohyal. Scale bar equals 2 mm. 
directed anterior process.

Fielitz (2002) reported only eight pectoral fin rays preserved in the 1969 material. We find there are 18 (CMN 56503) and the base of the fin is oriented horizontally. A pelvic girdle preserved in ventral view with associated fin rays (UALVP 55649) shows that the left and right girdles were probably only slightly separated from one another through the mid part of their lengths between the posterior end, where the median bar from each side contacted each other at the midline, and the anteriormost tips. One specimen shows the anterior tips overlapped, a second specimen shows the tips widely separated (UALVP 55702, Fig. 8), but this is an isolated pelvic girdle that seems somewhat

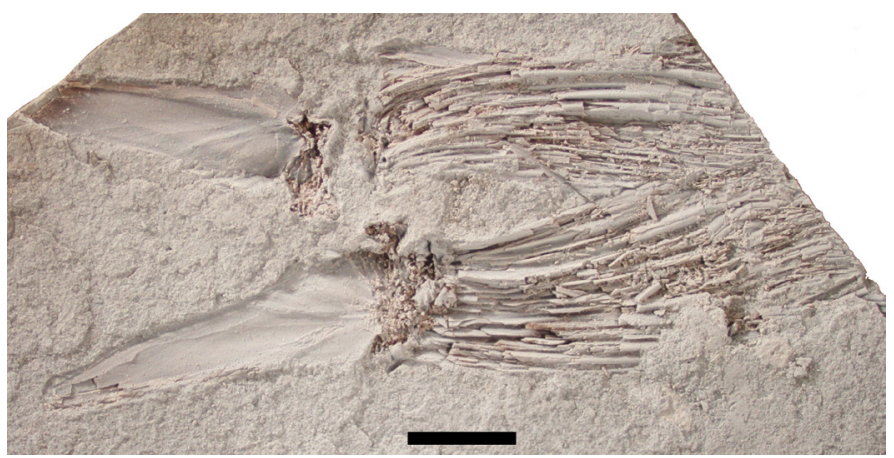

Figure 8. Avitosmerus canadensis, UALVP 55702.

Photograph of the pelvic girdle coated with ammonium chloride, anterior to left. Scale bar equals $2 \mathrm{~mm}$.

disarticulated. It does show clearly that the left and right halves were not sutured. There are 11 rays in the pelvic fin (UALVP 55649, UALVP 55702, and CMN 56507) rather than the six reported by Fielitz (2002). The pelvic fin rays meet the girdle below centrum 30 in CMN 56507, not positioned more anteriorly under the 24 th centrum, as previously noted by Fielitz (2002).

The single specimen in which a count of total vertebrae is clear (CMN 56507) has 52 centra plus the two ural centra for a total of 54, in agreement with the 1969 material. Specimen CMN 56503 preserves 13 supraneural (predorsal) bones (Fig. 7), more than the six previously described. The anterior ones are curved, broad anteroventrally and taper posterodorsally (also visible in UALVP 55649). These bones become progressively thinner more posterior in the series, and first eight are progressively longer. The posterior five are narrower, more upright bones that become progressively shorter posteriorly, with the last one being much smaller than the others. All the supraneurals are anterior to the first dorsal-fin pterygiophore. The six labelled supraneurals of Fielitz (2002:fig. 2) may correspond to the anterior broad supraneurals, with some of his unlabeled elements in that figure representing the narrow, upright posterior bones.

Two well-preserved caudal skeletons confirm some details

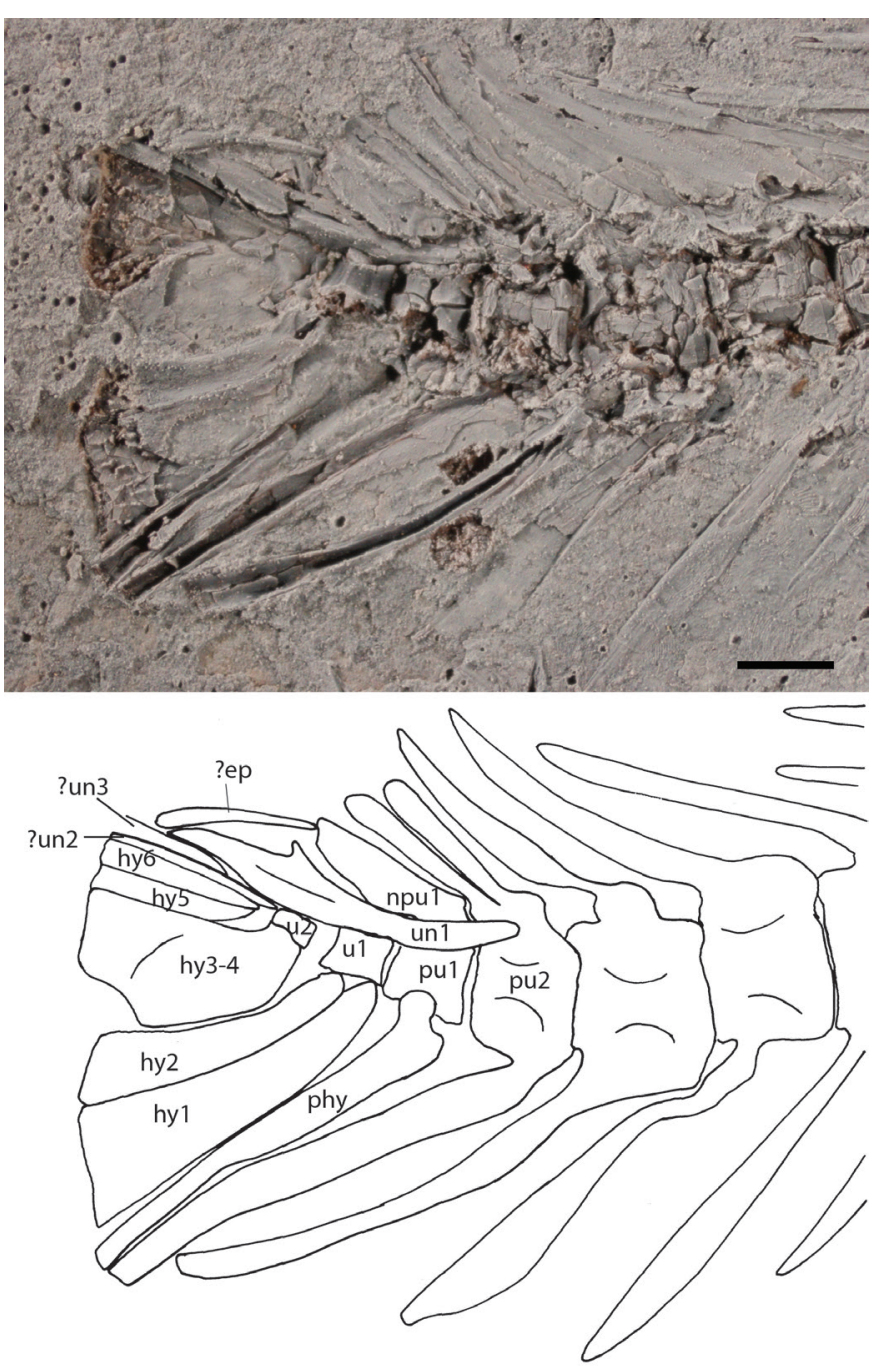

Figure 9. Avitosmerus canadensis UALVP 55701. Photograph of the caudal fin coated in ammonium chloride, with interpretive drawing. Scale bar equals $2 \mathrm{~mm}$.

described by Fielitz (2002); however, we interpret a number of elements differently. The two caudal fins figured by Fielitz (2002:fig. 8; CMN 17439 and 17435) were reported as being highly fused, with the first preural centrum, first and second ural centra (diural terminology), parhypural and first and second hypurals all fused together into a single element [although in the associated figures (Fielitz 2002:fig. $8 \mathrm{a}, \mathrm{b})$, the second ural centrum is indicated as a separate element]. In contrast, all of these elements are clearly seen as separate in the new material (UALVP 55701, Fig. 9, and UALVP 55703). A thin line of sediment is present between hypurals one and two, indicating these two are not fused. The parhypural is borne on a separate centrum (the first preural centrum; pu1) from that bearing the first and second hypurals (the first ural centrum; u1). Similarly, the second ural centrum (u2) is not fused to $\mathrm{u} 1$ or pu1, as previously reported. Hypurals three and four do appear to be fused together, as previously indicated (Fielitz 2002). The new material (Fig. 9) shows the form of the fused hypural 3 and 
4 to be very similar to that figured by Fielitz (2002:fig. 8) in having a posteroventral concavity and a thickening along the fusion zone. As reported by Fielitz (2002), there are an additional two narrow hypurals (five and six), and a stegural, as well as a long thin bone lying horizontally dorsal to the stegural, which he identified as an epural. This last could instead be a displaced caudal scute, based on its position; however, if so we cannot identify any epurals, and so prefer to consider this an epural. The first preural centrum has a broad, oval neural spine, as figured by Fielitz (2002:fig. 8). In the new specimen (Fig. 9) the neural spine of the second preural centrum is doubled.

With the information from the new material in mind, we reexamined the material figured by Fielitz (2002:fig. 8), and we believe the caudal skeletons can be reinterpreted as for the new material. Specimen CMN 17439 is in part and counterpart, with both pieces embedded in bioplastic and acid prepared from the exposed side. In the part figured by Fielitz (2002:fig. 8 a) most of the bone is missing and the impressions of the bone have little relief, leading to interpretation of fusion among elements. The part of CMN 17435 figured by Fielitz (2002:fig. 8b) was similarly prepared and the illustration is of embedded and acid-prepared material. This specimen is missing most of the bone and again the impressions are vague. Neither specimen contradicts the anatomical details as preserved in the new material figured here.

Unlike the 1969 material from the nodules, the 2010 material from the shales preserves scales with almost every specimen. These are small roughly circular cycloid scales with 11 to 14 circuli around a more or less central focus.

\section{DISCUSSION}

The information provided here is based on new specimens of two taxa previously described from the same locality, but from a different layer. The new specimens were preserved differently from the original material, which has allowed additional details of the anatomy to be discerned. With this additional information, we re-examined the proposed relationships of these fishes. Previously, we (Cumbaa and Murray 2008) suggested that Aquilopiscis wilsoni belonged to the Pachyrhizodontidae and Fielitz (2002) left Avitosmerus canadensis as a basal euteleostean.

\section{Relationships of Aquilopiscis wilsoni}

Cavin (2001) analysed the phylogenetic relationships of pachyrhizodontids and related fishes to determine the placement of Goulmimichthys arambourgi. Although a strict consensus tree was unresolved for the pachyrhizodontid genera, in his 50\% majority-rule tree, he found that Goulmimichthys was the sistergroup to Pachyrhizodus and those two together formed the sistergroup to Rhacolepis, with the three forming a monophyletic family
Pachyrhizodontidae. The three characters Cavin (2001) used to support this family are: six or fewer uroneurals present in the caudal fin, the first uroneural being forked anteriorly, and a hypurapophysis present. We cannot determine if the hypurapophysis is present in Aquilopiscis wilsoni, but the other two characters are clearly present. In Cavin's (2001) analysis, the Crossognathidae was far removed from the Pachyrhizodontidae.

Arratia (2008) included pachyrhizodontids and related fishes in a larger phylogenetic analysis of crossognathiforms; Pachyrhizodus was not included in her analysis. She found Apsopelix and Crossognathus formed a clade (Crossognathidae), as did Goulmimichthys and Rhacolepis (representing Pachyrhizodontidae), with these two families as sister group to each other. Notelops was found to be the sistergroup to these two families combined. This group of five genera was not formally named, but referred to as the 'Cretaceous crossognathiforms' (Arratia 2008). Most of the characters supporting these clades were homoplastic at some level within Arratia's (2008) tree. The clade uniting Notelops with the other genera was supported by five characters, however, four of these characters reversed their states within this group (Arratia 2008: characters 7, 11, 30 and 84). The remaining character, origin of the dorsal fin anterior to the level of origin of the pelvic fin (Arratia 2008: character 95) is present in Aquilopiscis wilsoni.

Arratia (2008) united Crossognathidae with Pachyrhizodontidae based on five characters. Three of these are present in A. wilsoni [Arratia 2008: character 48(2): articular fused with angular but not retroarticular; 64(1): posteroventral portion of preopercle broadly expanded; and 141(1): upper caudal fin rays not lying obliquely over and covering the upper hypurals]. The fourth character (55), absence of the gular, is unknown for $A$. wilsoni but it is likely absent. The fifth character given by Arratia (2008: character $35)$ for this group is the lack of teeth on the dermopalatine; $A$. wilsoni has teeth on the palatine, however, Goulmimichthys also has palatine teeth (Cavin 2001) as does Notelops (Forey 1973), so this character does not support this clade.

Aquilopiscis shares three characters with the Crossognathidae [Arratia 2008 character 86(1): dorsal intermuscular bones present [but these are also present in Notelops and Rhacolepis according to Forey (1977)]; 123(1): absence of two uroneurals (rather than three or four) extending anteriorly beyond the second ural centrum; and 184(1): vertebrae do not number about 40], but unlike crossognathids it has the articulation of the quadrate and anguloarticular behind the orbit, rather than placed below the posterior part of the orbit (Arratia 2008: character 46) and epipleural bones are associated only with the abdominal vertebrae, not the caudal ones [84(2)].

On the other hand, Aquilopiscis shares with Pachyrhizodontidae five characters [Arratia 2008 character 30(0): fourth and fifth 
infraorbital bones not fused; 87(1): canal of supracleithrum exiting bone at posteroventral margin; 124(1) seven or fewer hypurals; 136(0) dorsal procurrent rays positioned close to the epurals and uroneurals rather than the neural spines; 194(1) lateroparietal condition of the skull roof, in which the supraoccipital separates the parietal bones medially]. The sixth character for the Pachyrhizodontidae [Arratia 2008: 101(1) presence of hypurapophysis] as noted above cannot be determined in Aquilopiscis.

We do not consider the three characters that Aquilopiscis wilsoni seems to share with the crossognathids to indicate relationship between these taxa as one is also found in pachyrhizodontids (character 86), and another is not well defined (Arratia 2008: p. 89 character 184, "approximately 40 vertebrae (including preural centrum 1): absent [0]; present [1]"; this suggests that fewer than 40 vertebrae or more than 40 would be coded as the same state). The third character was also rather difficult to understand [Arratia 2008: p. 88 character 123 "Two uroneurals, rather than three or four, extending forward beyond the 'second' ural centrum: no uroneural present (0); absent (1); present (2); other condition: one uroneural present (3)"]; however, this character was rewritten by Arratia and Tischlinger (2010) as "Uroneurals extending forward beyond the 'second' ural centrum (diural terminology): no uroneural present [0]; three or four [1]; two [2]; one [3].” With the clarified character, we would not be correct in assigning $A$. wilsoni the same state as the crossognathids, because we would code $A$. wilsoni as having one uroneural extending forwards beyond the second uroneural (state 3 ) which would agree with the coding of the pachyrhizodontid representative Rhacolepis in the matrix of Arratia and Tischlinger (2010) rather than their coding for Crossognathus. Additionally, the structure in $A$. wilsoni seems quite different from one illustrated for Crossognathus (Patterson and Rosen 1977:fig. 21). Aquilopiscis wilsoni is therefore kept in the Pachyrhizodontidae as originally described.

Arratia (2008) did not examine the relationships among pachyrhizodontids. Cavin (2001), in his consensus tree, found Pachyrhizodus more closely related to Goulmimichthys, with Rhacolepis forming the sister group to those two genera. The uniting of Goulmimichthys and Pachyrhizodus was based on a homoplastic character, the presence of some fusion in the upper hypurals of the caudal skeleton, which is not present in Aquilopiscis.

\section{Relationships of Avitosmerus canadensis}

As has been pointed out by many authors (including more recently by Gallo et al. 2009, and de Figueiredo et al. 2012), Euteleostei is a very large group, and numerous small Cretaceous species have been left incertae sedis as basal euteleosteans with relationships unknown. These fossil fishes are aligned with Euteleostei, partly based on the absence of characters defining the other teleostean groups (such as the ventral scutes of Clupeomorpha, or the Weberian apparatus of Ostariophysi) and partly based on the presence of euteleostean characters (such as presence of a stegural with anterodorsal membranous outgrowth; see Wiley and Johnson (2010) for an overview of characters). However, relationships among the basal fossils have not been adequately studied.

Fielitz (2002) listed a number of characters for Avitosmerus that distinguished it from other basal euteleosts. We can now modify these characters with the information provided by the new material. Fielitz (2002) stated that Avitosmerus possessed supraneural pattern 2. This referred to the pattern noted by Johnson and Patterson (1996) in which the first supraneural develops separately from the rest of the series and in adults is seen to be larger or thicker than the others and separated from the rest of the series by a gap filled by one or more neural spines. Fielitz (2002) noted that only Avitosmerus among the basal euteleosts considered (Fielitz 2002:tab 1) had this pattern. We can now confirm that Avitosmerus does not show supraneural pattern 2; although the neural spines are displaced in CMN 56503, the first and second supraneural bones are touching each other along their length and are of similar robustness (Fig. 7). Avitosmerus is also similar to other basal euteleosts (Fielitz 2002:tab.1) in lacking a suprapreopercle. Avitosmerus also lacks the fusion of the parhypural with hypurals one and two, and lacks fusion between the first preural and first ural centrum. The presence of both hypurals one and two on a single centrum indicates Avitosmerus has ural centra one and two indistinguishably fused, but the next ural centrum (ural 2 of diurnal terminology, but presumably ontogenetically ural 3) is present and bears the upper hypurals. Among other basal euteleosts, Avitosmerus canadensis is superficially similar to Gaudryella gaudryi (UALVP 13356; Patterson 1970) in a number of features. The hyomandibulae of both taxa have a similar anteroventral projection, although that of G. gaudryi is longer (Patterson 1970:fig7c). The lacrimals of the two fishes are of similar shape and have several radiating branches of the sensory canal ending in pores along the ventral edge of the bone (Patterson 1970:fig 6). The shape of the dentary in G. gaudryi is somewhat different, in that the coronoid process has a large posterior component (Patterson 1970:fig. 8) which is lacking in $A$. canadensis. The left and right halves of the pelvic girdle of G. gaudryi (Patterson 1970:fig. 12c) meet anteriorly, which is not evident in $A$. canadensis, in which one specimen has the two halves displaced to overlap each other, and the other specimen that preserves the two halves has them separated throughout their lengths; however, the strong medial processes of the posterior ends are present in both.

Fielitz (2002) indicated that the branching pattern on the 
preopercle was unique to $A$. canadensis and not found in other Cretaceous euteleosts including G. gaudryi; however, the pattern of canals and pores is roughly similar between the two. The presence of a separate suprapreopercle in the 1969 specimens was considered by Fielitz (2002) to be unique to $A$. canadensis among Cretaceous euteleosts, but as noted, this element cannot be verified in the new material and may not be present.

The relationships among all these Cretaceous basal euteleosts clearly need much more study before we can begin to understand the evolution of the early euteleosts and their relationships with the living protacanthopterygians and neoteleosteans. Despite the new information provided here for Avitosmerus canadensis, we must leave this species incertae sedis within Euteleostei.

\section{ACKNOWLEDGEMENTS}

Field work for this project was funded by the Polar Continental Shelf Program (SLC), the Canadian Museum of Nature (SLC), and Natural Science and Engineering Research Council of Canada Discovery Grant 327448 (AMM). Fieldwork was conducted under Aurora Research Institute Scientific Research Licence \#14714 issued to S.L. Cumbaa. Our thanks to Rick Day (CMN) and Rob Holmes (CMN \& UALVP) for collecting material from Lac des Bois and companionship in the field, to Michel Picard (CMN) for the mineralogical analysis of the concretions, and to David Bardack for generously sharing his photographs from 1969 with us. Thanks also to the people of Norman Wells for their hospitality and generosity, particularly Larry Wallace, Carla Salikin and Sam and John Kivi. We are grateful to reviewers Gloria Arratia, Lionel Cavin and Adriana Lopez Arbarello, and the editor, Jordan Mallon, for providing many helpful comments to improve the manuscript.

\section{LITERATURE CITED}

Arratia, G. 1997. Basal teleosts and teleostean phylogeny. Palaeo Ichthyologica, 7:5-168.

Arratia, G. 2008. The varasichthyid and other crossognathiform fishes, and the break-up of Pangaea. In: L. Cavin, A. Longbottom and M. Richter (eds.) Fishes and the Break-up of Pangaea. Geological Society, London, Special Publications 295: 71-92.

Arratia, G. and H. Tischlinger. 2010. The first record of Late Jurassic crossognathiform fishes from Europe and their phylogenetic importance for teleostean phylogeny. Fossil Record 13:317-241.

Cavin, L. 2001. Osteology and phylogenetic relationships of the teleost Goulmimichthys arambourgi Cavin, 1995, from the Upper Cretaceous of Goulmima, Morocco. Eclogae Geologicae Helvetiae 94:509-535.

Cook, D.G. and J.D. Aitken. 1971. Geology, Colville Lake map-area and part of Coppermine map-area Northwest Territories. Geological Survey of Canada, Paper 70-12, Ottawa. 42 pp.

Cope, E. D. 1872. On the families of fishes of the Cretaceous formation in Kansas. Proceedings of the American Philosophical Society, Philadelphia 12:327-357.

Cumbaa, S.L. and A.M. Murray. 2008. New Late Cretaceous pachyrhizodontid and enchodontoid fishes and associated ichthyofauna from the Northwest Territories, Canada; pp. 229-256 in G. Arratia, H.-P. Schultze and M.V.H. Wilson (eds.), Mesozoic Fishes 4 - Homology and Phylogeny. Verlag Dr. Friedrich Pfeil, München.

de Figueiredo, F.J., V. Gallo, and A.F.P. Delarmelina. 2012. A new protacanthopterygian fish from the Upper Cretaceous (Turonian) of the Pelotas Basin, southern Brazil. Cretaceous Research 34:116-123

Fielitz, C. 2002. A new Late Cretaceous (Turonian) basal euteleostean fish from Lac des Bois of the Northwest Territories of Canada. Canadian Journal of Earth Sciences 39:1579-1590.

Forey, P. L. 1977. The osteology of Notelops Woodward, Rhacolepis Agassiz and Pachyrhizodus Dixon (Pisces Teleostei). Bulletin of the British Museum (Natural History) Geology 28:125-204.

Gallo, V., F.J. de Figueiredo, and S.A. Azevedo. 2009. Santanasalmo elegans gen. et sp. nov., a basal euteleostean fish from the Lower Cretaceous of the Araripe Basin, northeastern Brazil. Cretaceous Research 30:1357-1366.

Johnson, G.D. and C. Patterson. 1996. Relationships of lower euteleostean fishes; pp. 251-332 in M.L.J. Stiassny, L.R. Parenti and G.D. Johnson (eds.), Interrelationships of Fishes. Academic Press, San Diego.

Murray, A.M. and S.L. Cumbaa. 2013. Early Turonian acanthomorphs from Lac des Bois, Northwest Territories, Canada. Journal of Vertebrate Paleontology 33:293-300.

Patterson, C. 1970. Two Upper Cretaceous salmoniform fishes from the Lebanon. Bulletin of the British Museum (Natural History) Geology 19:207-296.

Patterson, C. and D.E. Rosen. 1977. Review of ichthyodectiform and other Mesozoic teleost fishes and the theory and practice of classifying fossils. Bulletin of the American Museum of Natural History 158:83-172.

Taverne, L. 1989. Crossognathus Pictet, 1858 du Crétacé inférieur de l'Europe et systématique, paleozoogéographie et biologie des Crossognathiformes nov. ord. (Téléostéens) du Crétacé et du Tertiaire. Palaeontographica, Abt. A 207:79-105.

Wiley, E.O. and G.D. Johnson. 2010. A teleost classification based on monophyletic groups. In: J.S. Nelson, H.-P. Schultze and M.V.H. Wilson (eds.) Origin and Phylogenetic Interrelationships of Teleosts, pp. 123-192. Verlag Dr. Friedrich Pfeil, München, Germany.

Yorath, C.J. and D.G. Cook. 1981. Cretaceous and Tertiary stratigraphy and paleogeography, Northern Interior Plains, District of MacKenzie. Geological Survey of Canada, Memoir 398. 76 pp. 